\title{
Development and Validation of HPTLC Method for Quantification of Biomarker $\beta$-Sitosterol in Derris heyneana (Wight and Arn) Benth
}

\author{
POOJA SHINDE and APARNA SARAF* \\ Department of Botany, The Institute of Science, \\ 15 Madame Cama Road, Fort, Mumbai 32, India \\ draparnasaraf@yahoo.co.in
}

Received 7 August 2016/ Accepted 3 September 2016

\begin{abstract}
Derris heyneana (Wight and Arn) Benth is a medicinal woody climber belonging to family fabaceae found in Western Ghats of Maharashtra. There are no reports of quantification of $\beta$-sitosterol from this plant. Hence, a simple and sensitive High-Performance Thin-Layer Chromatographic (HPTLC) method was developed for identification and quantification of biomarker $\beta$-sitosterol in different parts of Derris heyneana. HPTLC was carried out with mobile phase Toluene: Ethyl acetate: Glacial Acetic acid: formic acid (12:6.1:1 (v/v)) on precoated aluminium silica gel plates (Merck) and densitometric determinations were done at 540 after derivatization with anisaldehyde sulphuric acid. Validation of $\beta$-sitosterol was done for methanolic stem extracts. Highest amount of $\beta$-sitosterol was found in stem. The method was validated using $\mathrm{ICH}$ guidelines in terms of Linearity, precision, specificity and accuracy. The linearity range was found to be $0.1 \mu \mathrm{g}$ to $0.7 \mu \mathrm{g} / \mathrm{spot}$.
\end{abstract}

Keywords: $\beta$-sitosterol, Derris heyneana, Wight and Arn, Validation

\section{Introduction}

The use of herbal medicines is on a rise all over the world. People prefer natural products, which have fewer side effects and are more efficient, less expensive and have milder effects. The use of herbal is limited on the same level as pharmaceuticals as the efficacy and safety of herbals has to be proven and the quality control has to be established quality control is one of the major problems in rational use of herbal medicines. With many herbal medicines the active constituent is not known and genetic and environment factors may influence the concentration of secondary metabolites. A marker compound is utilized to standardize the plant material and determine the quality of herbal medicine.

Many times the active constituents are present in lesser quantity than the amount required to display their phytochemical activity and hence such plant materials utilized for herbal preparations are worthless. Hence, one of the important components of a quality control 
is to validate the identity and quantity of the active component in plant product. However, the path remains uncertain in terms of standardization of products along with safety and efficacy for universal acceptance. The analysis and quality control of herbal medicines are moving a step ahead towards an integrative and comprehensive direction, in order to tackle the complex nature of herbal medicines. High-performance thin layer chromatography (HPTLC) is one of the sophisticated instrumental techniques for qualitative and quantitative analysis of the herbs and herbal drugs. High performance thin layer chromatography (HPTLC) is an effective quality assessment tool for the rapid identification and evaluation of botanical materials ${ }^{1}$.

Literature survey reveals that not much phytochemical work has been carried on Derris heyneana. The plant is a good source of secondary metabolites. There are no reports of quantification of $\beta$-sitosterol from this plant. Hence, a simple and sensitive HighPerformance Thin-Layer Chromatographic (HPTLC) method was developed for identification and quantification of biomarker $\beta$-sitosterol in different parts of Derris heyneana. Derris heyneanais less known climber belonging to family fabaceae. It is large and woody climber with pink coloured flower and polished pods ${ }^{2-4}$. It is found at an altitude $3000 \mathrm{~m}$ above mean sea level along Western Ghats of Maharashtra ${ }^{5-7} . \quad \beta$-sitosterol found to have hypocholestrolemic ${ }^{8}$, immumno-modulatory ${ }^{9}$, antidibetic ${ }^{10}$, antioxidant ${ }^{11}$, angiogenic ${ }^{12}$, chemopreventive $^{13}$, anti-inflammatory ${ }^{14}$, neuroprotective activity ${ }^{15}$.

\section{Experimental}

Whole plant parts of $D$. heyneana were collected in the month of January 2015 from Sindhudurg district of Maharashtra. The plant was authenticated at Blatter's herbarium, St. Xavier's College, Mumbai. The accession number for Derris heyneana is 15055.

\section{Apparatus and Reagents}

CAMAG Automatic TLC sampler 4, CAMAG Twin trough glass chamber, CAMAG TLC plate heater III, CAMAG visualiser 150503 and CAMAG TLC Scanner IV equipped with Cats 1.4.6 version software. Methanol toluene, ethyl acetate, glacial acetic acids, and formic acid were of analytical reagent grade with $99.8 \%$ purity. All the chemicals used were obtained from Merck chemicals. Standard $\beta$-sitosterol was procured from Sigma Aldrich. Standard volumetric flasks and pipettes of class a grade were used for determination.

\section{Preparation of Standard Stock Solution}

Preparation of stock $(A)$ solution of $\beta$-sitosterol $(1 \mu \mathrm{g} / \mu \mathrm{L})$

Stock (A) solutions of $\beta$-sitosterol $(1 \mu \mathrm{g} / \mu \mathrm{L})$ was prepared in methanol. $10 \mathrm{mg}$ of standard $\beta$-sitosterol was accurately weighed and transferred to a $10 \mathrm{~mL}$ standard volumetric flask. The contents of the volumetric flask were initially dissolved in $5 \mathrm{~mL}$ of methanol by sonication and then diluted up to the mark with methanol.

Preparation of stock $(B)$ solution for $\beta$-sitosterol $(0.1 \mu \mathrm{g} / \mu \mathrm{L})$

From the standard stock (A) solution, $0.1 \mathrm{~mL}$ was transferred to a $10 \mathrm{~mL}$ standard volumetric flask. The contents of the flask were initially mixed in $5 \mathrm{~mL}$ of methanol by sonication and then diluted up to the mark with methanol. Thus a working stock solution of $\beta$-sitosterol of $0.1 \mu \mathrm{g} / \mu \mathrm{L}$ was prepared in methanol.

\section{Preparation of samples}

$\beta$-Sitosterol is freely soluble in methanol, hence methanol was used for extraction from plant powder during method development and validation for the plant. Plant extracts of the concentration $50 \mu \mathrm{g} / \mu \mathrm{L}$ were prepared. During the process, $500 \mathrm{mg}$ of powder of Derris 
heyneana was extracted with $10 \mathrm{~mL}$ of methanol. The mixture was sonicated for $30 \mathrm{~min}$ and it was kept overnight for extraction. It was filtered through Whatmann filter paper No. 1 and filtrate obtained was subjected to HPTLC for quantification and validation of $\beta$ - sitosterol.

\section{Method development}

Chromatogram was developed for $\beta$-sitosterol by selecting the mobile phase after trying several combinations of solvents. The best resolution was observed in the selected (Toluene: Ethyl Acetate: Glacial Acetic Acid: Formic acid (12:6:1:1) (v/v/v)) mobile phase or solvent system. The optimized saturation time was observed as $20 \mathrm{~min}$. The developed HPTLC plate was dried at $120^{\circ} \mathrm{C}$, derivatized with anisaldehyde sulphuric acid reagent and again heated to identify compact bands. Densitometric analysis was performed at absorption maxima of wavelength $540 \mathrm{~nm}$ in absorbance-reflectance mode. HPTLC conditions are given in Table 1.

Table 1. Chromatographic conditions for HPTLC studies

\begin{tabular}{ll}
\hline \multicolumn{1}{c}{ Parameters } & \multicolumn{1}{c}{ Description } \\
\hline Stationary phase & $\begin{array}{l}\text { Silica gel } 60 \mathrm{~F}_{254} \text { precoated on aluminium sheet } \\
\text { Toluene: ethylacetate: glacial acetic acid: formic } \\
\text { acid }(12: 6: 1: 1)(\mathrm{v} / \mathrm{v} / \mathrm{v})\end{array}$ \\
& $20 \mathrm{mins}$ \\
Chamber saturation & $8 \mathrm{~mm}$ \\
Band length & $80 \mathrm{~mm}$ \\
Developing distance & Anisaldehyde sulphuric acid \\
Derivatizing reagent & $5 \mathrm{mins}$ (After development) \\
Plate drying & $10 \mathrm{mins}$ (After derivatization) \\
& $540 \mathrm{~nm}$ \\
\hline
\end{tabular}

\section{Method validation}

Validation of the developed method has been carried out as per the ICH guidelines for linearity, precision, accuracy, limits of detection (LOD) and quantification (LOQ), specificity and System suitability studies.

\section{Quantitation of $\beta$-sitosterol}

The external standard method is generally used for quantification analysis in TLC studies as it assures accuracy and precision in quantitative analysis. A chromatogram was developed using standard $\beta$-sitosterol with different concentration ranging from $1 \mu \mathrm{L}$ to $7 \mu \mathrm{L}$ and leaf, root, stem extract with same concentration of $20 \mu \mathrm{L}$, plotted separately on HPTLC plate. A calibration curve was obtained by plotting standard peak area against concentration.

\section{Linearity range}

For determining this factor $20 \mu \mathrm{L}$ of leaf, root and stem extract of plant and series of 7 spots of different volumes ranging from 1-7 $\mu \mathrm{L}$ was applied on HPTLC plate. After derivatization, the plate was scanned and a linearity curve was prepared with respect to peak area $v s$. concentration per spot.

\section{Precision}

Precision (intra-day) and accuracy of the assay were evaluated as per the ICH norms. Intra-day precision was performed by application of the six bands (each $3 \mu \mathrm{L}$ ) of standard $\beta$-sitosterol solutions $(0.1 \mu \mathrm{g} / \mu \mathrm{L})$ to a HPTLC plate, the densitogram and peak areas were recorded. 


\section{$L O D$ and $L O Q$}

Sensitivity was determined by establishing the limit of detection (LOD) and limit of quantitation (LOQ). They were determined at a signal to noise ratio of 3:1 and 10:1 respectively as per the ICH guidelines, standard deviation (SD) of response and slope was calculated for LOD $(\mathrm{DL}=3.3 \times \mathrm{SD} / \mathrm{S})$ and LOQ $(\mathrm{DL}=10 \mathrm{xSD} / \mathrm{S})$.

\section{Specificity (Selectivity)}

In specificity studies, assay and impurity method was performed using the stem extract, methanol, solvent system of Toluene: Ethyl Acetate: Glacial Acetic Acid: Formic acid $(12: 6: 1: 1)(\mathrm{v} / \mathrm{v} / \mathrm{v})$ for $\beta$-sitosterol with chamber saturation of 20 minutes with filter paper Whatmann No.1 along with standard solution of $\beta$-sitosterol.

\section{System suitability}

The system suitability experiment was carried out by spotting $3 \mu \mathrm{L}$ of $\beta$-sitosterol solution separately on different HPTLC plates. These solutions were spotted six times each in the chromatographic conditions. Peak area and retention factor were studied to evaluate the suitability of the system.

\section{Results and Discussion}

\section{Method development}

The developed method was found to be effective in the separation of constituents present in the leaf extract and exhibiting sharp peaks of standard $\beta$-sitosterol with the selected mobile phase when observed under wavelength of $540 \mathrm{~nm}$. Compact, symmetrical and high resolution bands of $\beta$-sitosterol were obtained at $\mathrm{R}_{\mathrm{f}} 0.59 \pm 0.03$. The developed method was found to be quite selective with good baseline resolution.

\section{Quantification}

Quantification of $\beta$-sitosterol was done in all plant parts of Derris heyneana. Maximum amount of $\beta$-sitosterol was found in stem extract. The identity of the band of $\beta$-sitosterol in extracts was confirmed by comparing $\mathrm{R}_{\mathrm{f}}$ value of extracts with the chromatogram of standard $\beta$-sitosterol solution. The standard $\beta$-sitosterol solution with volume ranging from 1 to $7 \mu \mathrm{L}$ yielded better results and hence were used for the analysis. Similarly 3 readings of standard sample solution were used for the purpose of quantification as per the ICH guidelines (Table 2).

\section{Linearity}

Linearity of compound $\beta$-sitosterol was validated by the linear regression equation and correlation coefficient (Figure $1 \& 2$ ). The linear correlation coefficient $r=0.999$ obtained indicates a perfect positive correlation between the concentrations of $\beta$-sitosterol and the peak areas. The RSD of the peak areas for all concentration of $\beta$-sitosterol is always much less than $2 \%$ which indicates more reliability of the results.

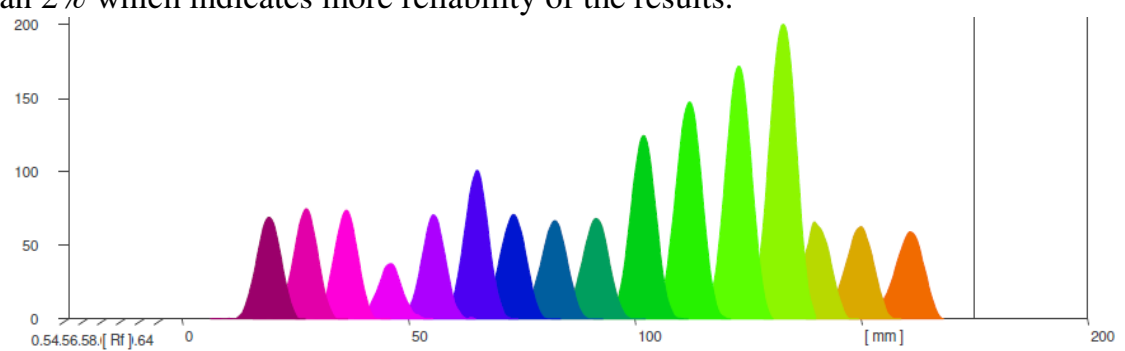

Figure 1. Densitogram for linearity of $\beta$-sitosterol 


\section{Recovery}

The peak area responded well when plant extract (zero value) was spiked by $80 \%, 100 \%$ and $120 \% \beta$-sitosterol. The average accuracy in terms of area and recovery of $\beta$-sitosterol is not affected by more than $10 \%$ when extract was spiked $\pm 20 \%$ over and above $3 \mu \mathrm{L}$ of standard $\beta$ sitosterol solution (Table 3 \& Figure 3).

Table 2. The $\mathrm{R}_{\mathrm{f}}$ values and peak areas corresponding to the serial dilutions of $\beta$-sitosterol and fixed amount of stem, root and leaf extract of Derris heyneana

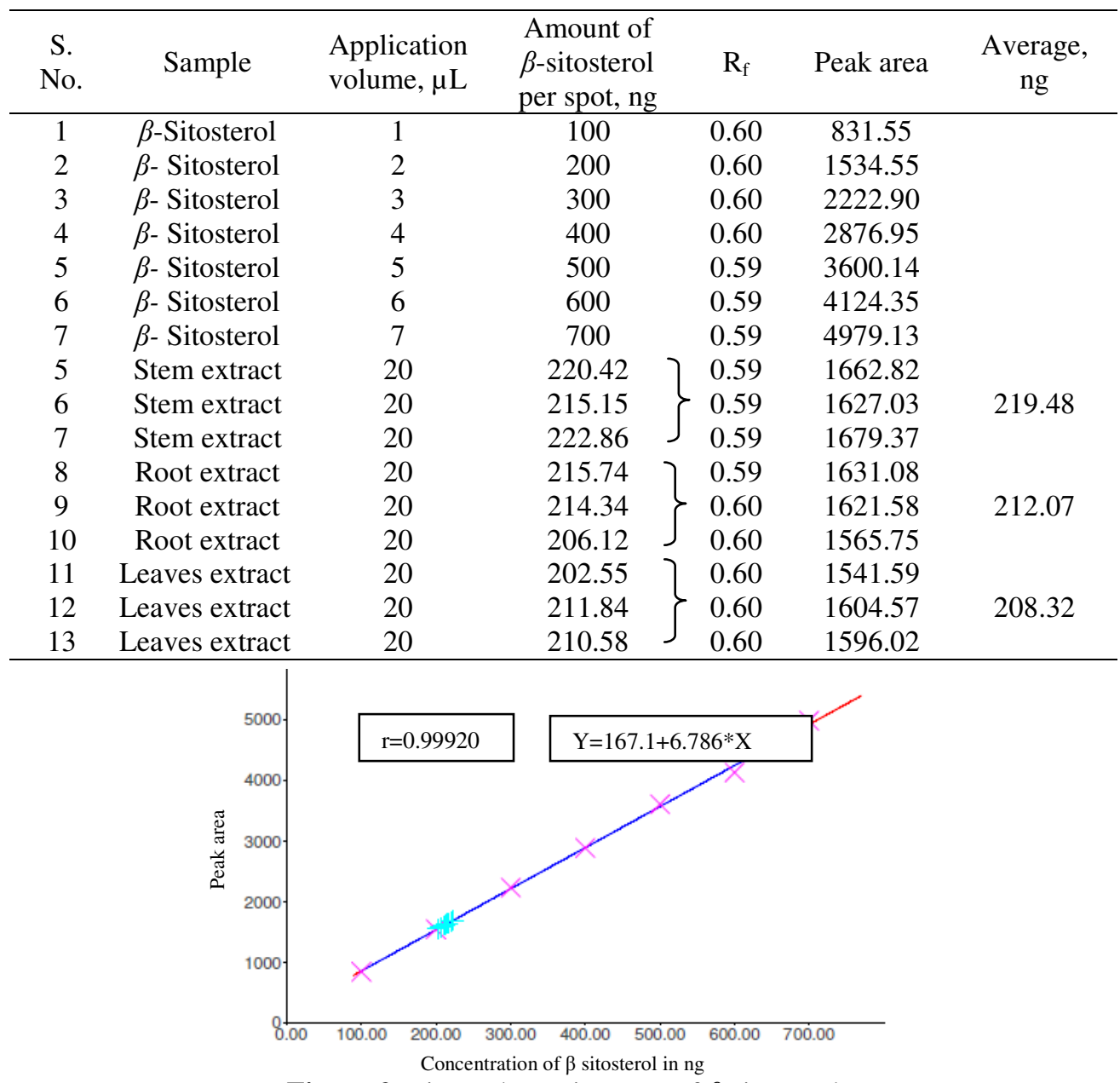

Figure 2. Linear dynamic range of $\beta$-sitosterol

Table 3. Recovery studies of $\beta$-sitosterol in plant extract when spiked by $80 \%, 100 \%$ and $120 \%$

\begin{tabular}{cccccc}
\hline Marker & $\begin{array}{c}\text { \%Marker } \\
\text { added }\end{array}$ & $\begin{array}{c}\text { Marker added } \\
\text { in } \mu \mathrm{L}\end{array}$ & Area & $\begin{array}{c}\% \\
\text { Recovery }\end{array}$ & $\begin{array}{c}\text { Average } \\
\text { recovery }\end{array}$ \\
\hline \multirow{3}{*}{$\beta$-sitosterol } & 80 & 2.4 & 1837 & 93 & \\
& 100 & 3 & 2151 & 90 & $90 \%$ \\
\hline \multicolumn{5}{c}{ *average of 3 readings } \\
& 120 & 3.6 & 2192 & 88 & \\
\hline
\end{tabular}




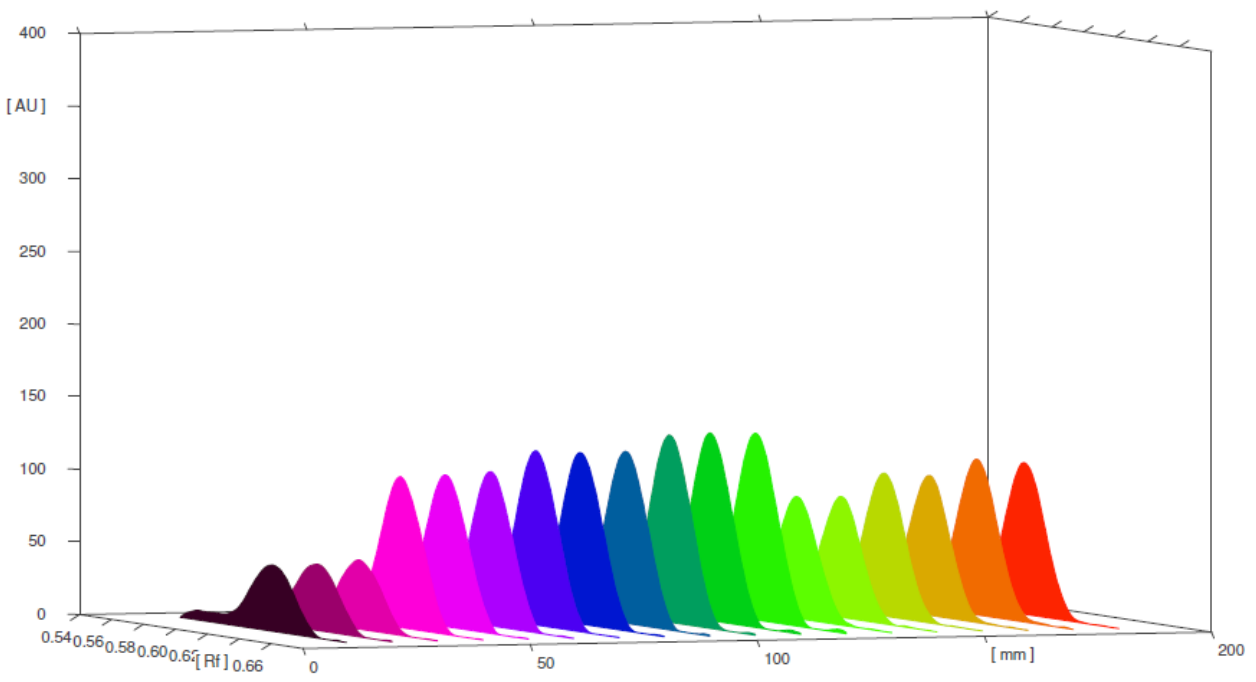

Figure 3. Recovery densitogram of $\beta$-sitosterol for stem extract of Derris heyneana

\section{Precision}

Intra-day precision of the assay for $\beta$-sitosterol demonstrated good precision of the proposed method. $3 \mu \mathrm{L}$ of $\beta$-sitosterol was loaded on the HPTLC plate. The \%RSD value $(n=6)$ in intra-day was found to be below 2.5 .

\section{Intra-day precision or repeatability}

As per the ICH guidelines similar bands (each $3 \mu \mathrm{L}$ ) of standard $\beta$-sitosterol solutions $(0.1 \mu \mathrm{g} / \mu \mathrm{L})$ were run on a HPTLC plate on different time of the day, the densitograms and peak areas were recorded (Figure 4). The mean, standard deviation, and coefficient of variation (\%) were calculated for peak area and $\mathrm{R}_{\mathrm{f}}$. The HPTLC profile obtained after derivatization show the analyte eluted to the same distance thus showing same $\mathrm{R}_{\mathrm{f}}$ in all the samples loaded on the plate. The $\%$ relative standard deviation of the peak areas for each loading of $\beta$ sitosterol is less than 2.5 which indicates more reliability of the results for herbal drugs.

\section{Inter-day precision}

The peak areas of standard $\beta$-sitosterol were recorded for three consecutive days. The values of mean peak area, standard deviation and related standard deviation were calculated for standard $\beta$-sitosterol on three different days. The results are given in Table 4 . As the values of $\%$ relative standard deviation of the peak areas of $\beta$-sitosterol for all sample solutions are below 2, it shows that the method is precise for performing the analysis.

\section{LOD/LOQ for $\beta$-sitosterol}

Limit of detection (LOD) for $\beta$-sitosterol was found to be $0.1 \mu \mathrm{g} / \mu \mathrm{L}$ Limit of quantitation (LOQ) for $\beta$-sitosterol was found to be $0.3 \mu \mathrm{g} / \mu \mathrm{L}$. This indicated the sensitivity of the instrument for the quantification of above compound.

\section{Specificity}

This method is found to be highly specific. HPTLC plate for specificty shows bands of $\beta$-sitosterol only in standard and stem extract. No corresponding bands were observed in diluent (methanol) and mobile phase 


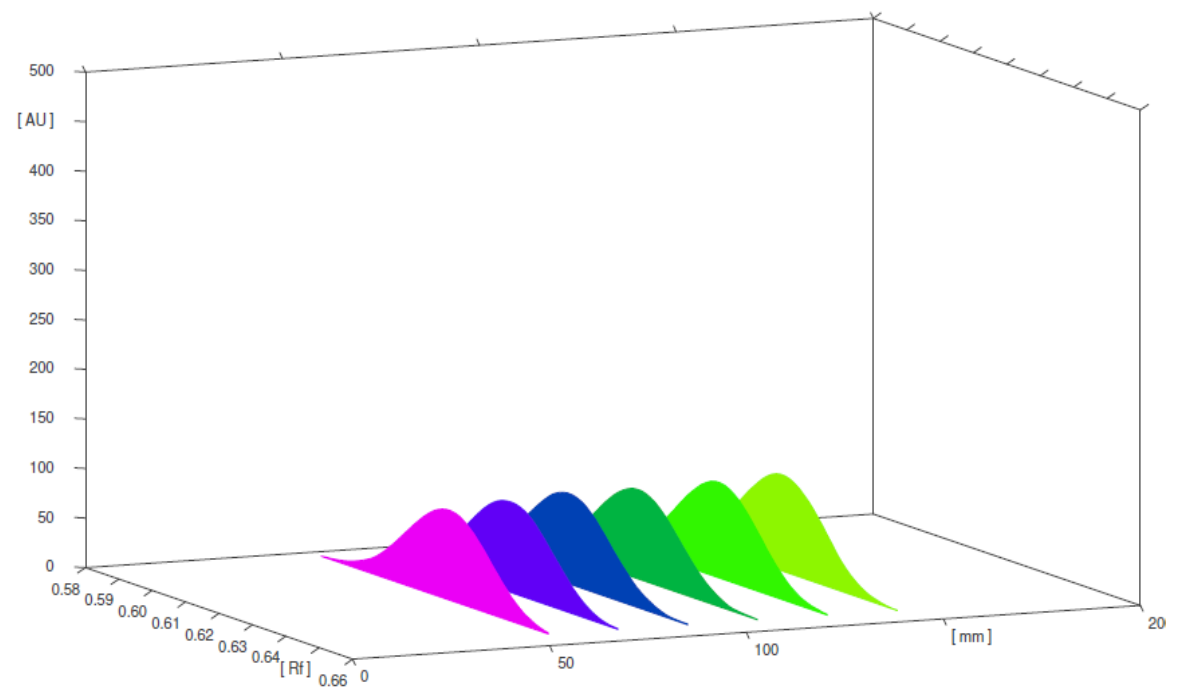

Figure 4. 3D densitogram for intra-day precision of $\beta$-sitosterol

Table 4. Inter-day precision for $\beta$-sitosterol

\begin{tabular}{ccccc}
\hline \multirow{2}{*}{ S. No. } & Quantity of & \multicolumn{3}{c}{ Peak area of $\beta$-sitosterol } \\
\cline { 3 - 5 } & $\beta$-sitosterol & Day 1 & Day 2 & Day 3 \\
\hline 1 & $0.3 \mu \mathrm{g}$ & 1406.51 & 1534.55 & 1315.83 \\
2 & $0.3 \mu \mathrm{g}$ & 1433.20 & 1488.03 & 1340.11 \\
3 & $0.3 \mu \mathrm{g}$ & 1406.85 & 1455.77 & 1316.98 \\
4 & $0.3 \mu \mathrm{g}$ & 1467.13 & 1504.85 & 1323.75 \\
5 & $0.3 \mu \mathrm{g}$ & 1461.87 & 1522.54 & 1334.87 \\
6 & $0.3 \mu \mathrm{g}$ & 1425.92 & 1524.41 & 1272.23 \\
& Mean & 1433.5 & 1505.0 & 1373.3 \\
& S.D. & 0.58 & 0.60 & 0.59 \\
& \%R.S.D. & 1.8 & 1.9 & 1.8 \\
\hline
\end{tabular}

\section{Conclusion}

A new validated HPTLC method has been developed for identification, quantification of $\beta$ sitosterol from methanolic extract of dried powder of root, stem and leaves of Derris heyneana (Wight and Arn) Benth. This method was validated in terms of linearity, accuracy, precision, specificity, which shows that this method can be used for routine quality control analysis.

\section{Acknowledgement}

The Authors are grateful to ANCHROM, Mulund for providing necessary facilities to carry out this work.

\section{References}

1. Amit Saraf K, Srilata Srinivas and Alka Chaturvedi, Res J Pharm Biol Chem Sci., 2016, 7(4), 471-476.

2. Almeida M R, Flora of Maharashtra, Oriental Press, Mumbai, 1998, 2, 58-60.

3. Talbot W A, Forest Flora of Bombay Presidency and Sind, Photozincographic Department, Poona, 1909, 1, 436. 
4. Singh N P and Karthikeven S, Flora of Maharashtra State, Dicotyledones, Vol.1, Flora of India, Series-2, Botanical Survey of India, Calcutta, 2000, 663-668.

5. Cooke T, The Flora of Bombay Presidency, Taylor Francis, London, 1902, 1, 405.

6. Almeida S M, Flora of Swantwadi, Scientific Publishers, Jodhpur, 1990, 1, 129.

7. Sanjappa M, Legumes of India, Bishen Singh Mahendra Pal Singh, Dehera Dun, $1991,146$.

8. Zak A, Zeman M, Vitkova D, Hrabak P, Tvrzicka E ,CasLek Cesk,1990,129,1320-1323.

9. Bouic P J, Etsebeth S, Liebenberg R W, Albrecht C F, Pegel K and Van Jaarsveld P P, Int J Immunopharmacol, 1996, 18(12), 693-700.

10. Radika M K, Viswanathan P and Anuradha C V, Nitric Oxide, 2013, 32, 43-53, DOI:10.1016/j.niox.2013.04.007

11. Baskar A A, Numair K S, Paulraj M G, Alsaif M A, Muamar M and Ignacimuthu S, $J$ Med Food, 2012, 15(4), 335-343; DOI:10.1089/jmf.2011.1780

12. Moon E J, Lee Y M, Lee O H, Lee M J, Lee S K, Chung M H, Park Y I, Sung C K, Choi J S and Kim K W, Angiogenesis, 1999, 3, 117-123.

13. Ovesna Z, Vachalkova A and Horvathova K, Neoplasma, 2004, 51(6), 407-414.

14. Prieto J M, Recio M C and Giner R M, Plant Med Aromat, 2006, 5(3), 57-62.

15. Shi C, Wu F, Zhu X and Xu J, Biochim Biophysic Acta, 2013, 1830(3), 2538-2544; DOI:10.1016/j.bbagen.2012.12.012 